\title{
THE USE OF INSURANCE CODES OF PRACTICE - ARE CONSUMERS GETTING A "FAIR GO"
}

\author{
David Clarke*
}

Voluntary codes of practice are currently favoured in New Zealand as a means of providing a framework for self regulation by industry groups. The insurance industry is no exception. A number of industry bodies have adopted codes of practice, which include general guidance and disciplinary codes.

This article examines these voluntary codes of practice and questions whether consumers benefit from this form of insurance regulation. This is not a speculative enquiry. Because of the importance of insurance as a mechanism for risk transfer to our society, our economy, and in particular, to consumers, a clear understanding of these codes of practice, and in particular their legal effect and their benefits and limitations as a rule-making mechanism is essential.

\section{WHY CODES OF PRACTICE? - POLITICAL AND ECONOMIC INFLUEN.CES}

To better understand the insurance industry's codes of practice ${ }^{1}$ and the reasons they have been adopted in their current form, we need to understand the context in which the codes have been adopted. Because: ${ }^{2}$

* Barrister and Solicitor of the High Court of New Zealand. This paper is based on the author's LLM research paper, D Clarke "Consumer Expectations and Insurance Codes of Practice" (1995) LLM Research Paper, VUW.

1 These codes are: the Insurance Council ("IC") Fair Insurance Code, the Health Insurance Association of New Zealand ("HIANZ") Code of Practice for Health Insurance Underwriters, the Life Office Association of New Zealand ("LOA") Code of Business Practices for Life Insurance Companies, the Life Underwriters Association of New Zealand Inc ("LUANZ") Code of Ethics and Professional Conduct Guidelines, the Insurance and Investment Advisers Association ("IIAA") Code of Professional Ethics the Corporation of Insurance Brokers of New Zealand ("CIBNZ") code of practice, and the Independent Insurance Brokers Association (NZ) Inc ("IIBA") code of practice.

2 A I Ogus Regulation Legal Form and Economic Theory (Clarendon Press, Oxford, 1994) 1. 
..."regulation" is fundamentally a politico-economic concept and, as such, can best be understood by reference to different systems of economic organisation and the legal forms which maintain them...

we must examine the insurance industry's codes of practice in the context of the systems of economic and political organisation prevalent in New Zealand in the 1990s.

Historically, New Zealand has had a mixture of different forms of insurance regulation with the state playing a dominant role regulating the industry using legislation and directly participating in the insurance sector. ${ }^{3}$ Extensive state intervention in the insurance sector is consistent with New Zealand's experience of government from the late 19th century until 1984. This experience has had two main strands: ${ }^{4}$

1 The dominance of central government; and

2 The acceptance of the idea that government had a central interventionist role to bring about collectively desired outcomes.

In more recent times, where problems have been identified with the insurance industry and its operating practices ${ }^{5}$ government has prevailed upon the industry to act as a responsible corporate citizen through adherence to codes of practice developed by the industry with input from consumer groups. ${ }^{6}$ This change of attitude can be linked to political and economic developments since $1984^{7}$ which have lead to a turning away from the belief that government intervention is "both a necessary and sufficient condition for economic success and rising living standards". 8

Since 1984 there has been a withdrawal or devolution of government from economic and other activities and a shift of in responsibility, for what were previously government functions, from central government to subsidiary and different levels of government and to institutions outside the government altogether. ${ }^{9}$ Part of this withdrawal has involved a

3 For example, the government responded to the operation of a New Zealand insurance tariff system by enacting legislation to set up the State Fire Insurance Office to break the tariff.

4 P McKinlay "Historical Background" in P McKinlay (ed) Redistribution of Power? Devolution in New Zealand (Victoria University Press, Wellington, 1990) 7.

5 Ministry of Consumer Affairs Study of Insurance Practices (Wellington, 1993) 2.

6 Ministry of Consumer Affairs Guidelines on Developing a Code of Practice (Wellington, 1993).

7 Prompted by the oil shock in 1974 and New Zealand's debt burden after the "think big" projects.

8 Above n 4, 11.

9 For a detailed discussion see P McKinlay, above $\mathrm{n} 4$. 
process of regulatory reform characterised by less regulation from the centre ${ }^{10}$ and a far greater emphasis on self regulation by particular industry groupings utilising non-binding codes of conduct for raising standards of market behaviour. ${ }^{11}$

\section{A Self regulation}

Self regulation is a broad concept covering a wide range of institutional arrangements. These arrangements differ according to a number of variables. These variables include whether the arrangements covers all suppliers in a market, the degree of formality involved (in particular whether the scheme draws its legitimacy from some legislative framework) and the degree to which groups outside the industry regulated contribute to the system by way of co-operation, consultation or enforcement: ${ }^{12}$

All regulatory systems require a number of tasks to be performed: as an exercise in policy making, the goals of a regime must be established: those goals must be translated into the principles and rules which control behaviour; and there must be procedures for explicating and enforcing them.

Who then sets the goals for the self regulation by the insurance industry?

Historically, the insurance industry in common with other industries has set the goals for self regulation and for the rules governing industry conduct. Prior to 1990 the goal of industry for self regulation has been to restrict competition between the participants in the industry and to limit market entry. ${ }^{13}$ This focus was manifested in codes of practice which dealt with matters such as membership of associations of companies or professional groups and restrictions on advertising and business practices. ${ }^{14}$ It can be argued that the goals for self regulation and the use of codes of practice are now set by government. Since 1990, the growth of the idea of "consumerism" and the emphasis placed by government on an open and competitive economy has proved a catalyst for a move away from schemes of self regulation posing barriers to competition. With the devolution of state participation in the economy and the emphasis which is now placed on individual responsibility, there is now a far

10 See, B Wheeler "Regulation and Devolution" in P McKinlay, above n 4, 79.

11 D J Harland "Post-Sale Consumer Legislation for New Zealand - A Discussion of the Report to the Minister of Justice by Professor David H Vernon" (1988) 3 Canta LR 410, 430.

12 Above n 2, 99.

13 In the case of the insurance industry, self-regulation historically focused on the maintenance of the New Zealand tariff system, for a discussion of this idea see A Henderson Competition and Co-operation - The Insurance Council of New Zealand and the General Insurance Industry in New Zealand 1895 - 1995 (Insurance Council of New Zealand and the Historical Branch, Department of Internal Affairs, Wellington, 1995).

14 For example, the LUANZ Code of Ethics. 
greater focus on individual rights ${ }^{15}$, and in the particular context of the commercial sector, on consumer rights.

The influence of this "new" consumer policy on insurance can be found in the Ministry of Consumer Affairs report on Insurance Practices which for the first time attempted to identify comprehensive information about insurance practices in New Zealand. ${ }^{16}$ The study was based on an expression of concern that the insurance industry was not changing in response to consumer's needs and expectations. Of particular concern was the fact that the industry resolved disputes on the basis of its established practices and traditions rather than on a basis of substantive fairness.

The IC's Fair Insurance Codes, the CIBNZ code, the IIAA Code and the IIBA code of practice arguably have been drafted in response to the Ministry of Consumer Affairs report and the economic and political forces underlying it. The preparation of the Fair Insurance Code and the development of the IIAA Code of Ethics, illustrate a attitude to self regulation focusing far more on the regulation of matters which would contribute to consumer participation in the market and a move away from prescribing matters which could limit consumer choices by restricting competition. In the case of the IIAA Code of Ethics there has been a shift in focus in the self regulation of this group from internal discipline of a professional group to an emphasis on the importance of providing a valuable service to consumers. The IIAA are making a conscious attempt to reposition themselves as "professional advisers" and away from their previous "role" as sales agents for insurers. ${ }^{17}$

\section{B The Adoption of the LOA Code-Abuse of Securities Regulation}

There have been other "external" events which have contributed to the adoption of insurance codes of practice. The LOA code of practice was promulgated because of the "abuse" of the operation of securities regulation. The LOA Code of Business Practices is promulgated under provisions inserted in 1988 in the Securities Act 1978 as a result of the case of Marac Life Assurance Ltd $v$ Commissioner of Inland Revenue. ${ }^{18}$ The provisions

15 See for example. the New Zealand Bill of Rights Act 1990, the Human Rights Act 1993 and the Health and Disability Commissioner's Code of Consumer Rights 1996.

16 Above $\mathbf{n} 5$.

17 A discussion with the Executive Officer of the IIAA. Competitive forces in the economy such as the increase in telephone sales and banks and other institutions selling insurance products may also have contributed to this re-positioning in an attempt to gain a competitive edge by offering a superior service.

18 [1986] 1 NZLR 694, where the Court of Appeal decided that the exemption which existed at that time in the Securities Act 1978 relating to life insurance also related to life insurance products which were in legal form life insurance but in economic substance ordinary investments. Marac had been issuing debentures in the form of life insurance to take advantage of the exempt status of life insurance under the Securities Act 1978. Discussions with a Ministry of Justice Legal Adviser suggest that changes also occurred because the Securities Commission 
allow the Securities Commission to grant "authorised status" to life insurance companies who observe standards for the carrying on of life insurance business prescribed or approved by the Securities Commission. ${ }^{19}$

\section{THE RELATIONSHIP BETWEEN INSURANCE CODES OF PRACTICE AND GOVERNMENT REGULATION OF THE INSURANCE INDUSTRY}

One of government's stated goals for the contemporary use of codes of practice is to clarify the rights and responsibilities of traders in a specific market. In this sense codes are said to be an adjunct to government regulation. ${ }^{20}$

\section{A Codes as an Adjunct to Government Regulation}

If codes are merely an adjunct to government regulation then they act as an aid to understanding the rules and principles of government regulation rather than having direct legal effect. In this sense government regulation provides the primary legal rules or obligation rules for the insurance industry while code of practice are secondary legal rules which do not impose any duties at all, rather they act as rules of change, adjudication and recognition. ${ }^{21}$

Rather than involving the imposition of duties on member companies the insurance industry's voluntary codes of practice may rely for adherence on their "ideological effect". This ideological effect has a material existence in the sense that voluntary codes of practice are embodied in the social practices of individuals in the insurance sector and in the institutions and organisations within which these social practices take place. ${ }^{22}$

took the opportunity given by the amendment to set up regime that looked at the general probity of life insurance products as a form of investment.

19 Under s 7A(2) of the Securities Act 1978, the Securities Commission may declare a life insurance company to be authorised for the purposes of the Securities Act 1978 authorised companies do not have to comply with certain provisions of the Act relating to prospectuses, trustees trust deeds and the prohibitions on door to door selling. Companies which are not authorised have to comply with the Acts provisions. To obtain and retain authorised status s 7B(a) of the Securities Act 1978 requires life insurance companies to observe standards for the carrying on of life insurance business prescribed or approved by the Securities Commission. The LOA code contains such standards, and outlines information and behaviour standards which must be observed during the life insurance selling process. The current LOA code was approved by the Commission on 18 October 1994.

20 Above n 6, 1.

21 This analysis is based on the categories of legal rules developed by Professor Hart and which are discussed in J W Harris Legal Philosophies (Butterworths, London 1985) 105-114.

22 Based on the ideas discussed in R Simon Gramsci's Political Thought - An Introduction (Lawrence and Wishart, London, 1985) 59-60. 
There is some empirical evidence to suggest that businesses value a good reputation for its own sake and as part of the essential goodwill on which a business trades. ${ }^{23}$ This point may be especially true in the insurance industry where companies trade on trust. Adverse publicity may damage this trust and subsequently profits. Adverse publicity may also lead to a ground swell of public opinion calling for increased government intervention.

\section{B Insurance Codes of Practice as an Alternative to Government Regulation}

Far from acting as an adjunct to government regulation, codes of practice may in fact be promoted as an alternative to government regulation. Government has suggested that codes of practice can provide certain public benefits including: ${ }^{24}$

(a) addressing problems of market failure by way of information disclosure and/or the prohibition of certain practices;

(b) raising standards of trading and service performance;

(c) encouraging compliance with existing law;

(d) monitoring for code compliance; and

(e) establishing procedures to handle complaints and resolve disputes.

A number of the public benefits above have been traditionally provided by government regulation.

In a practical sense, there may be a temptation to use codes of practice as an alterative to government regulation on the basis that their use in promoting public benefits removes moral pressure for further government regulation and supervision of an industry. ${ }^{25}$ In this sense codes of practice are used as an alternative to further government regulation. ${ }^{26}$ If codes of practice are to operate as an alternative to government regulation rather than as anjunct to such regulation then from a legal analysis this raises the issue of the accountability of the insurance industry for the content and the implementation of its codes of practice. There is also an important accountability issue here, in that the insurance industry may both make its own rules and enforce them. From a traditional legal perspective, there are a number of

23 Ayres and J Braithwaite Responsive Regulation Transcending the Deregulation Debate (Oxford University Press, 1992) 22.

24 Above n 6, 1.

25 This idea would appear to be the rationale behind the approach taken in, D Brash and I McLean A Prudential Regime for Insurance Companies - A Report for the Minister of Justice (Wellington, 1993) 9-10.

26 The use of statements of practice by the insurance industry in the UK, arguably to forestall government regulation on the recommendation of the UK Law Commission, provides a practical example. 
mechanisms which are used to secure accountability: judicial control, procedural control, for example, through the office of an ombudsman, or accountability to some body or agency.

\section{PRACTICAL ASPECTS OF THE USE OF INSURANCE CODES OF PRACTICE}

\section{A The Insurance Industry's Objectives for the Codes}

A number of the codes promulgated in the insurance context have a statement of objectives to explain to the industry and to consumers why the codes were adopted. Where a code does not have a specific statement of its objectives it is possible to make an assessment of those objectives from the overall tenor of the code. The "stated" objectives of the various insurance codes of practice, elicited from the codes themselves, fall into two broad categories:

1 The provision of guidance to industry on agreed standards of practice. ${ }^{27}$

2 To provide consumers with some material benefit. For example, a certain quality of service. $^{28}$

The codes whose objectives fall within the second category are essentially codes of selling practices. The codes in the second category also focus heavily on the need to meet the information needs of consumers. One of the basic objectives of any regulation produced for the benefit of consumers is to address the information problems facing consumers in the modern economy. Insurance in particular is a complex area both legally and from the perspective of making a choice as to which insurance product to buy. Given the problems faced by consumers as a result of the multiplicity of different options available to satisfy their expectations of insurance, consumers need accurate information to make informed choices.

Codes of practice are used by the insurance industry in an attempt to provide such information. For example, the HIANZ, LOA and IIAA codes in particular focus on regulation aimed at meeting the information needs of consumers to allow them to make informed choices. Further research could be carried out to ascertain whether consumers find the information provided about, and in, insurance codes of practice, useful as a basis for making assessments of insurance products and services.

27 The LUANZ, the CIB and the IIBA codes are fall within this category. These codes are primarily codes of ethical conduct aimed at their respective members.

28 The second version of the IC's Fair Insurance Code, the LOA Code, and the HIANZ code and the IIAA codes fall in this category. 


\section{B How are the Objectives of the Codes Met?}

The codes of practice used in the insurance context range in approach from codes providing general statements of objectives, ${ }^{29}$ which members are "expected" to meet, to codes providing prescriptive performance standards for members. ${ }^{30}$ Codes which provide for general statements of objectives undoubtedly have an advantage of flexibility. From a consumer perspective however, their application is uncertain and the flexibility involved provides the members of the code concerned with a wide degree of discretion. One practical example is the way in which the second version of the Fair Insurance Code deals with the issue of disclosure. The code states that members must advise consumers of their duty to disclose all facts which are material to an insurance company's assessment of risk. The code however, contains no performance standards against which a member company's compliance with this requirement can be judged. Equally, there is no indication in the code of how insurers are expected to provide this advice, whether by a simple statement or by a written warning in policy proposals. There is also no indication of the steps which insurance intermediaries must take to explain the disclosure requirements to consumers.

This position can be contrasted with the prescriptive provisions of the HIANZ code. Clause 12 of the HIANZ code requires specific mention to be included in member policy proposals of matters which would affect the policy and in particular the receipt of benefits under the policy. Clause 12.3 .6 requires members to make a general statement of the circumstances which may restrict or invalidate benefits in the proposal form. Clause 12.4(d) includes a specific disclosure warning. Clause 15.4 of the HIANZ code requires intermediaries to explain the health insurance policy to consumers. Clause 15.5.3 goes on to require intermediaries to specifically draw to the consumer's attention the consequences of non-disclosure.

The prescriptive codes of practice therefore, provide for a greater degree of certainty for consumers as to their application and provided a practical basis on which to measure member performance.

The uncertainty inherent in codes which contain general statements of objectives only, could be mitigated by the provision of performance standards for measuring member performance. Of all the insurance codes of practice, the IIAA code comes closest to this model. The IIAA code sets out eight individual codes dealing with specific matters. Each has an objective, a statement of the code's application and a number of principles which are to be observed to meet the objective.

29 See, for example, the IC's Fair Insurance Code.

30 See, for example, the HIANZ and LOA codes. 


\section{What are the Practical Benefits of Insurance Codes of Practice for Consumers?}

In considering the question of whether insurance codes of practice offer any benefits for consumers, it must be remembered that consumers already possess a number of existing legal rights which impose correlative duties on members of the insurance industry. For example, when considering codes of practice issued by insurance industry bodies, the existence of the mutual duty of utmost good faith must be kept in mind. ${ }^{31}$ Given this, it is arguable that many of the codes of practice promulgated in the insurance context do not provide consumers with any new or improved rights and in fact can be categorised as expositions of existing consumer rights and industry duties. The IIBA, CIB, LUANZ and IIAA codes, for example, for the main part do not create "new" consumer rights.

There are advantages to consumers however, even in re-stating existing rights and duties especially where consumers may be ignorant as to the existence or the extent of these rights and duties. Codes which set out existing rights and duties can also provide practical advantages for consumers and industry where they are used as a means to explain the specific application in the insurance context of the provisions of government regulation. The IIAA code for example, has attempted to explain how the Fair Trading Act 1986 affects specific aspects of the practices of the Association's members. ${ }^{32}$

One particular piece of "general" consumer protection legislation which may have a significant impact on insurance is the Consumer Guarantees Act 1993. None of the insurance codes currently provide any detailed exposition of the application of the act to their member's practices, or provide any practical examples for consumers of how the Act applies in the insurance context. When the Consumer Guarantees Act was being developed, the government had Professor D H Vernon of the University of Iowa prepare a model ${ }^{33}$ on which to base the proposed new Act. Professor Vernon ${ }^{34}$ suggested a statutory regime which involved the creation of codes of responsible practice. Professor Vernon's scheme envisaged a two tiered system for such codes. ${ }^{35}$

The top tier was to have been a statutory code of responsible practices. The second tier, to add flexibility to the legislation, was to have consisted of supplier drafted special codes of responsible business practices. The supplier drafted codes while compatible with the

31 A number of the provisions of the Fair Insurance Code arguably are duties which any insurer would owe an insured in terms of the duty of utmost good faith.

32 See the provisions of code 4 of this code of practice.

33 Professor D H Vernon An Outline for Post-Sale Consumer Legislation in New Zealand (Government Printer, Wellington, 1987).

34 For a detailed discussion of the Vernon Report, see D J Harland, above n 11.

35 Above n 33, 17-18. 
statutory code where to be drafted to reflect the special circumstances of individual businesses. It was intended that the supplier drafted codes would only come into effect after they had been certified by the Minister of Consumer Affairs. ${ }^{36}$

Even though Professor Vernon's model was not adopted in the Consumer Guarantees Act 1993, his idea of providing for industry based codes of responsible practices could be adapted as a model for revising the provisions of existing insurance codes of practice. For example, Professor Vernon's model would be useful to explain how the general warranties in the Consumer Guarantees Act 1993 apply in the insurance context. Similarly, the model could be used to provide for an exposition of the requirements of a number of statutory schemes in the insurance context.

One significant "new right" which has been established by the use of a number of codes of insurance practice, is the access provided to alternative dispute resolution schemes, such as the scheme operated by the Insurance and Savings Ombudsman. All of the insurance codes provide for some scheme for the resolution of disputes between scheme members and consumers. ${ }^{37}$ The standard of the service and subsequent benefits provided to consumers by these schemes is variable. The number of existing schemes could also potentially be confusing for consumers. It may in fact be preferable if all the schemes were standardised. For example, the Insurance and Savings Ombudsman scheme could be applied to all the codes of insurance practice.

\section{The Government's Perspective - Codes of Practice as an Alternative to Government Regulation}

The Ministry of Consumer Affairs considers that there are a number of practical advantages for consumers and for industry groups flowing from the use of voluntary codes of practice as a framework for industry self regulation as opposed to government regulation. ${ }^{38}$ Each of these reasons will be considered in turn paying particular attention to the insurance context.

\section{Self regulation may be more cost effective than government regulation.}

There are practical advantages for government from self regulation. Persuading the private sector to self regulate is "cheap" when compared to the cost of government intervention to establish, maintain and enforce statutory regulation of an industry. Whether consumers benefit from this approach requires further consideration. Given that

36 Professor Vernon also suggested that the Minister of Consumer Affairs should have the power to impose codes on recalcitrant suppliers who failed to draft a code or who drafted an unsatisfactory code.

37 See above $n 5,39-65$, for an assessment of the merits of the various schemes.

38 Above n 6, 2. 
consumers or taxpayers are likely to meet the cost of whatever scheme of regulation is adopted cost is an important issue. Financial cost is however, only one method of assessing the merits of self regulation as opposed to government regulation. To test the validity of the Ministry of Consumer Affair's statement, there needs to be an assessment of the practical advantages of self regulation from the perspective of both insurer and consumer.

It follows that criteria need to be developed to measure the worth of codes of practice from the perspective's of each of these parties based on factors such as the quality of the outcomes achieved as well as the cost involved. To establish such criteria empirical data would need to be collected both as to:

(a) what consumers expected from insurance; and

(b) the effectiveness of voluntary codes of practice to meet these expectations as opposed to government regulation.

To balance this exercise the perspective of the insurers would also need to be ascertained and analysed. Such a study could usefully be the subject of further research in this area and may require a multi-disciplinary approach looking at legal, sociological and economic considerations and could make up for the dearth of empirical data about the effectiveness of self regulation and the use of voluntary codes of practice in the insurance context . Empirical data could be gathered in a number of ways: by interviewing insurers and consumers, or by analysing complaints received by the insurance industry ${ }^{39}$ and by other agencies.

It could be argued that if the insurance industry wishes to use codes of practice and self regulation instead of government regulation they must assume responsibility for collecting statistics which would help accurate assessments to be made about the effectiveness of their use of codes of practice. ${ }^{40}$ The Insurance and Savings Ombudsman would seem a logical

39 There is considerable room for improvement in this area. The Insurance Council did not maintain a comprehensive complaints data base until 1992. Since that date it has maintained a complaints data base which breaks complaints down by category of insurance. The Life Offices Association has only collected complaint information since 1993. The Association breaks down its data base by reason for complaint. The greatest number of reasons for complaints have been non-compliance with its code and about inadequate service or lack of information

40 The Ministry of Consumer Affairs, above n 5, suggest that information should be collected by industry about:

(a) the number of complaints lodged and by whom;

(b) the number found to be in breach of the code and why;

(c) the number found not to be in breach of the code and why;

(d) who was complained about;

(e) time taken to deal with complaints; 
candidate to make such assessments from data collected and could publish the results in the form of reports modelled on the reports published by the Parliamentary Ombudsman.

\section{Codes can be industry specific and written in language readily understandable to public and members of the industry.}

This is certainly a major advantage of the use of codes of practice. Plain English is not however the only issue surrounding accessibility to the rules set out in codes. There is the important issue of the physical availability of the code of practice to the public. While it is a legal requirement to publish legislation for the purpose of ensuring its accessibility to the public $^{41}$ there is no equivalent legal requirement to make codes available. ${ }^{42}$ This could prove to be a practical problem especially if the insurance industry was not prepared to devote sufficient resources to the dissemination of codes. Ideally a copy of the relevant code of practice should be provided to a consumer before the consumer decides whether they wish to do business with the party covered by the code.

\section{An industry with some "ownership" of a code may be more committed to making it work.}

Whilst this statement may be true, it is important to remember that consumers will also have an important stake in the codes of practice used in the insurance industry. For that reason, and to ensure that the perspective of the consumer is recognised, there needs to be a mechanism for consultation on the proposed contents of a code during its initial formulation and during subsequent amendments. The Ministry of Consumer Affairs recognises the importance of consultation to ensure that the perspective of consumers as stake holders in codes of practice are also taken into account. ${ }^{43}$ The consultation issue also needs to be considered in the context of the issue of the accountability of the framers of codes of practice for the contents of the code. Where consultation is a statutory requirement the Courts have intervened to clarify the meaning of consultation and to ensure its proper completion. ${ }^{44}$ It may be difficult to convince a court to exercise equivalent controls over consultation in this

(f) how many items were monitored under each category;

(g) how many breaches were found through monitoring;

(h) number and type of sanctions imposed; and

(i) number of decisions appealed and the outcome of those appeals.

41 The Acts and Regulations Publication Act 1989.

42 This is a major disadvantage of the use of codes of practice identified in, The Law Reform Commission of Victoria Codes of Practice (Report No 39, July 1991) 39.

43 For a discussion of the advantages of consumer consultation see above $n 6,4$.

44 For example, see Wellington Airport Ltd v Air New Zealand [1993] 1 NZLR 671. 
context. ${ }^{45}$ Even if this option is available to consumers, the cost of asking a court to impose such controls could prove prohibitive.

4 Code of practice can address systematic complaints about an industry and can act as a form of industry quality control.

Literal compliance with this concept may result in codes of practice being used in a reactive rather than a pro-active manner to improve standards. An empirical study such as that suggested earlier in the paper, may provide a more comprehensive basis on which to prepare an insurance code of practice. The statement also assumes that the quality of the information gathered will allow an accurate assessment to be made of common themes of complaint. The way in which an industry gathers complaint information would therefore require careful scrutiny. It is possible that an industry group could be selective both about the data it gathers and the manner of its collection which may lead to real issues of concern about industry practice being obscured. This fact suggests the need for standardisation of the data collected by the industry and the need to audit the data collection process.

\section{Self regulation can improve an industry's public image}

This is obviously an advantage from the insurance industry's perspective but not for a consumer's. It is important that the existence of a scheme of self regulation of an industry not be allowed to obscure the need for statutory reform in appropriate cases. ${ }^{46}$ Codes of practice have been used in the insurance context in the United Kingdom as a substitute for law reform. This development has been the subject of much criticism. ${ }^{47}$

\section{One sector of an industry can attempt to gain a competitive advantage by using a code to contend that it meets higher standards than its competitors.}

If this objective is to be achieved there needs to be objective criteria to assess the worth of competing codes of practice. One method of measuring the respective merits of competing codes of practice could be to have some independent agency assess codes of practice against objective criteria with the aim of providing each company with a rating, for example in respect of the quality of service which they provide. One possible model for such a scheme could be the model used in the Insurance Companies (Ratings and Inspections) Act $1994 .{ }^{48}$ The statement also highlights the problem of the coverage of codes of practice. If codes of

45 The question of whether administrative law controls could and should be applied to the promulgation and use of voluntary codes of practice could be the subject of further research.

46 Some commentators may argue that the existence of business self regulation means that there is no need for government intervention.

47 Law Commission Insurance Law: Non-disclosure and breach of warranty (1980) Cmnd 8064.

48 Currently used to provide information about the financial soundness of insurers. 
practice are not compulsory it may be that a company may choose not to promulgate or contribute to the promulgation of a code. Such a decision would make consumer choice between the relative merits of companies problematic.

\section{Codes are more flexible than regulation and can be easily changed to reflect the dynamic nature of the market place.}

Codes are said to be a flexible mechanism ${ }^{49}$ in the sense that they can be drafted to meet the specific needs of a particular industry and can be amended just as simply. They can be used where there is a need for a degree of technical expertise and knowledge of practices which may not be present in government and can result in rule making which can be tailored to the needs of a particular industry.

The codes which have been prepared in New Zealand tend to be simpler for a lay person to understand than traditional legislation. This is because the language used is less formal and some codes even provide commentaries and examples to illustrate their provisions. In this sense codes may be a method by which rules can be made governing the insurance relationship which are simple and therefore more accessible to consumers. ${ }^{50}$ In this sense they may offer some advantages over delegated legislation such as statutory regulation.

The Victorian Law Reform Commission ${ }^{51}$ has raised concerns about the use of codes of practice in this respect. The Commission is concerned that the use of codes could make the use of statutory regulations unattractive and uneconomic for government. The basis for this concern is constitutional because the increasing prevalence of the use of codes of practice could have the result of weakening Parliament's control over the setting of regulatory standards.

\section{Complaint making bodies set up under a code can resolve complaints more quickly than government bodies or the courts and at less cost to the parties to a dispute.}

It is clear that alternative dispute resolution schemes set up in conjunction with codes of practice as part of industry self regulation can resolve complaints more quickly and cheaply than the courts and at a reduced cost to insurers, and the state and often at no cost to the consumer. There is however, the well known legal principle that no-one should be a judge in their own cause. This principle raises a concern about the essential legitimacy of industry based codes of practice and dispute resolution mechanisms linked to them.

49 Flexible in the sense that they can be changed quickly because of the nature of the processes used in developing the code without the need to go through the formal processes of promulgation followed by "traditional" legislative instruments.

50 Bearing in mind the comments earlier in this article.

51 Above n 42, 19. 


\section{E Limitations of Insurance Codes of Practice}

\section{The legal effect of insurance codes of practice}

One major difficulty with the current codes of practice used in the insurance context is that they have no legal effect. ${ }^{52}$ For the consumer, this means that they have no means of enforcing the provisions of the codes. Consequentially, consumers must rely on the promulgators of the insurance codes to administer the codes in a fair and effective fashion. What does this tell us of the relationship between consumers and the insurance industry?

The relationship between consumers and the insurance industry is one of dependence. Dependence on insurers to meet claims and dependence on professional groups such as brokers to provide sound and effective advice. Similarly, the relationship between consumers and the insurance industry as promulgators of insurance codes of practice is a relationship of dependence. Consumers are ultimately dependent on the promulgators of the codes to deliver any promised benefits from the code.

The use of the model of voluntary codes of insurance practice may ultimately benefit the companies and individuals who have agreed to be bound by such codes of practice rather than consumers. This is because such companies and individuals retain a measure of freedom and discretion as to whether they will comply with the code or whether they choose to opt out of the code's coverage altogether.

\section{Are the promulgators of the code accountable?}

Because the use of voluntary codes of practice places a great deal of discretion in the hands of the promulgators of the codes, their use does raise the question of whether the promulgators of codes should be accountable for the exercise of their discretion. To the extent that insurance codes of practice claim to provide benefits for consumers, consumers may argue that the promulgators of codes of practice should be accountable to them for the exercise of this discretion.

From a legal perspective the traditional methods for ensuring accountability for the exercise of a discretion are administrative law tools based on due process requirements and judicial control. There may be some scope to convince the courts to use administrative law tools to examine a discretion exercised by the promulgators of insurance law codes of practice. The Court of Appeal in Finnigan $v$ New Zealand Rugby Football Ltd Inc ${ }^{53}$ was prepared to review the decision of an essentially "private body". The President of the Court of Appeal suggested that the issues in the Finnigan case had some analogy to public law

52 With the exception of the LOA code which is promulgated under the Securities Act 1978.

53 [1985] 2 NZLR 159. 
issues. ${ }^{54}$ Equally, it could be argued that the exercise of a discretionary power by insurance rule makers involves issues which are closely analogous to public law issues.

Even if it were possible, however to convince a court to apply administrative law tools such as judicial review to the exercise of the discretion by the promulgators of insurance codes of practice, the cost for consumers of using the courts to hold the promulgators of codes of practice accountable would be prohibitive. The principal technique which is used to attempt to hold the promulgators of insurance codes of practice accountable to consumers for the content and application of codes of practice is direct bargaining between consumers and the promulgators of codes. Historically, voluntary codes of practice essentially amounted to "agreements" between competing players in the insurance industry which more recently have provided benefits for consumers as "third party beneficiaries".

In an attempt to provide "legitimacy" from a consumer perspective for the codes of practice produced as a result of such agreements, the insurance industry, encouraged by government, ${ }^{55}$ invites consumer inputs into these agreements. For example, the HIANZ and the CIBNZ have invited consumer input into the contents of their codes of practice to provide a measure of consumer accountability. In a similar vein the IIBA consulted with the Ministry of Consumer Affairs to ensure consumer input into the preparation of their code of practice. Some insurance codes also provide for a measure of accountability to consumers for the enforcement of the code by involving consumers in disciplinary procedures. ${ }^{56}$

There are limitations from a consumer perspective of providing for accountability based solely on consensus:

(a) The industry may be unwilling to cooperate. A number of the codes used in the insurance context have no consumer input into their preparation or into their enforcement.

(b) There may be major power imbalances in favour of the industry which may mitigate against substantive consumer influence on the content and the application of codes of practice. $^{57}$

(c) It may be impossible to reach a consensus position in respect of controversial issues.

54 Above n 53, 179.

55 Ministry of Consumer Affairs, above $\mathbf{n} 5$.

56 For example, the CIBNZ and the IIBA have consumer representation on their complaints panels.

57 Since by inviting consumers to participate in the preparation of codes of practice, the industry is essentially inviting consumers to become "a party" to the contract encapsulated in the codes, issues arise about the relative bargaining power of the "parties". 
From a consumer perspective, it may be preferable if a government agency approved the insurance industry's codes of practice and had the power to amend and even prescribe codes of practice if the industry proved unwilling or incapable of producing codes of practice which reflected consumer interests and concerns. It would also be useful if such an agency had a supervisory role to ensure that industry discretion in respect of the operation of codes of practice was properly exercised.

\section{The coverage of codes of practice}

A major limitation of the use of voluntary codes of insurance practice from a consumer perspective is the coverage offered by codes. The majority of the codes used in the insurance context rely on voluntary membership. It follows that the codes may not cover the whole industry and as a result some consumers may be disadvantaged if they decide to contract with a company or an individual who is not covered by a code. Non of the current codes of practice used in the insurance context provide for blanket coverage of the industry group regulated.

Another aspect of the difficulties presented by the coverage of voluntary codes is the problem that a member of an industry group covered by a code is free to "opt out" of the codes coverage leaving affected consumers without remedies under the code. The power to "opt out" may be used by an industry member to escape sanction under the code. In such a case enforcing any penal provisions provided for under the code against that "member" may be problematic or impossible. The problems raised for consumers by incomplete coverage of insurance codes of practice could be remedied by the use of a statutory "default regime".

Such a regime would operate by providing for default provisions which would apply to those members of the insurance industry who were not covered by an industry code of practice, included those members of the industry who "opted out" of the coverage of a code of practice to escape sanction. The regime could provide consumers who were affected by such a party with access to statutory redress against such a party.

\section{CONCLUSION}

The aim of this article has been to consider the practical benefits to consumers of non binding insurance codes of practice and to answer the question - Do consumers benefit from this form of insurance regulation?

This article has noted that insurance codes of practice are currently used in two ways. To restate the existing rights and duties of consumers and the insurance industry and to provide certain public benefits for consumers which historically may have been provided by government regulation. It is suggested that both approaches have the potential to provide practical benefits for consumers. 
None of the current insurance codes of practice however, fully utilise the potential of codes of practice as a means of explaining the application of new general statutory requirements to the insurance context. It is also noted that there are number of impediments which prevent consumers from taking advantage of the use of codes of practice as a means of providing public benefits. Two models are presented for further consideration to address these issues.

1 Codes could be used as a means by which the existing legal rights and duties of the consumers and industry could be clearly set out in plain English supplemented by practical examples. Used in this way codes could for example, be used to provide an explanation of how a piece of legislation such as the Consumer Guarantees Act 1993 applied in the insurance context.

2 Codes could be used as an alternative to government regulation to provide public benefits to consumers. Codes of practice do have real benefits as a flexible rule making mechanism, the negative aspects of the use of codes from a consumer perspective could be remedied by providing for:

(a) codes of practice issued by industry and approved by some public authority who also had the power to prescribe the terms of codes of practice where the industry were unwilling or unable to provide a code which fairly balanced consumer expectations and industry interests;

(b) a statutory default scheme of regulation for those individuals and companies who chose not be covered by an industry code or who opted out of an industry code;

(c) the provision of legally enforceable remedies for consumers (available at little or no cost to consumers); and

(d) the provision of democratic accountability for the content of codes, including compulsory requirements for consultation and the power to disallow the provisions of a code in appropriate circumstances.

In summary, there is a need to reconsider the way in which non-binding codes of practice are used in the insurance context. Before making a final decision about the future use of codes, it is suggested that empirical research needs to be carried out on whether all consumers benefit from a regulatory approach which focuses on consumer choice or whether a regulatory approach incorporating a measure of consumer protection is required. It is important that we do not assume that all consumers have the ability to act in a rational manner when making choices about insurance. Whatever model of insurance regulation is adopted it is important that it is flexible enough to take account the differing needs and capacities of consumers. 